\title{
Barium sulfate crystallization dependence on upper rim calix[4]arene functional groups
}

\author{
Andrew Baynton ${ }^{a}$, Mark I. Ogden ${ }^{a}$, Colin L. Raston ${ }^{b}$, and Franca Jones*a \\ Received (in $X X X, X X X)$ Xth $X X X X X X X X X 200 X$, Accepted Xth $X X X X X X X X X 200 X$ \\ ${ }_{5}$ First published on the web Xth $X X X X X X X X X 200 X$ \\ DOI: $10.1039 / b 000000 x$
}

\begin{abstract}
Although the effects of $p$-sulfonated and $p$-phosphonated calix[4]arene on barium sulfate morphology and settling rate are similar, their ability to form mesocrystals of material are markedly different. The $p$-phosphonated calix[4]arene results in the formation of fibre bundles similar to those previously observed during barium sulfate crystallization in the presence of di-block copolymers. The 10 isostructural sulfonated calix[4]arene, however, affords material consistent with the initial formation of mesocrystals which subsequently fuse. This material shows significant beam damage when viewed under a transmission electron microscope (TEM) suggesting incorporation of the sulfonated calix[4]arene, although there was no evidence of this from $\mathrm{X}$-ray diffraction and atomic force microscopy (AFM) studies. We hypothesise that this calixarene is incorporated without significant change in structure of the material, and that the interaction of the macrocycle with the barium sulfate lattice is sufficiently weak that surface AFM imaging is effective in 15 removing it from the surface.
\end{abstract}

Crystallization is important in many areas, for example, in pharmaceutical processes ${ }^{1}$ and within biological organisms (biomineralization). ${ }^{2,3} \mathrm{~A}$ current focus in crystallization science is to engineer particle formation, ${ }^{4}$ with particle size and shape influencing important handling properties, and more ${ }^{5-7}$ This can be readily achieved by introducing additive molecules, and there is significant literature related to how additives or impurities impact on the size and morphology of inorganic or organic particles (for example refs ${ }^{8-10}$ ). In our work on engineering particles, we use barium sulfate as a model system since it 20 is relatively simple to crystallize, has only one known crystal structure at ambient temperatures and pressures, and is not plagued by the speciation issues associated with carbonate-based systems. Barium sulfate is also of interest in its own right, as it is a common component of scale (unwanted crystallization) in off-shore oil production, ${ }^{11}$ and is even found as a biomineral in some organisms. ${ }^{12-14}$

In general, phosphonate containing additives are potent inhibitors of barium sulfate crystallisation, more so than carboxylates or sulfonates, ${ }^{15}$ although 25 stereochemistry ${ }^{16}$ and ionic charge ${ }^{17}$ also play a role. We have previously reported ${ }^{18}$ on the morphological impact of calix[4]arenes on different functional groups (one sulfonated and one phosphonated) in the para position of the macrocyclic framework and here we further develop their impact on barium sulfate precipitation.

\section{Methods and Materials}

30 The calix[4]arene molecules, Figure 1, $p$-sulfonated calix[4]arene, $\mathbf{1},{ }^{19}$ and the $p$-phosphnated calix[4]arene, $\mathbf{2},{ }^{20}$ were prepared in-house. Aspects of the experimental details have been previously reported ${ }^{18}$ and full details can be found in the supplementary information.

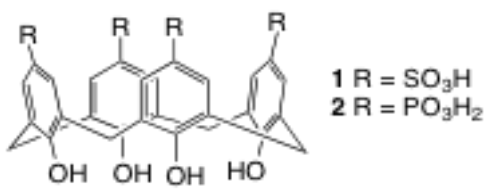

Figure 1. $p$-Sulfonated (sulfonic acid) and $p$-phosphonated (phosphonic acid) calix[4]arene

\section{Results}

Conductivity

The inhibition of barium sulfate for the two calixarene molecules is quite different, depending on the functional group attached to the upper rim. $p$ Phosphonated calix[4]arene inhibits the reaction over the 3 hour time period with as little as $0.013-0.014 \mathrm{mM}$ while $0.2 \mathrm{mM}$ of the sulfonated calixarene 40 only inhibits barium sulfate precipitation by $34 \% .{ }^{18}$ Ethylenediaminetetraphosphonate is a strong inhibitor and complete inhibition is observed at $\sim 0.001$ $\mathrm{mM}^{23}$ making the phosphonated calixarene $\sim 10$ times weaker than this inhibitor despite both having 4 phosphonate groups available for interaction with the crystal surface. Thus, the spatial arrangement of phosphonate groups in the calixarene backbone in this case is detrimental to its inhibitory efficacy. The sulfonated calixarene is weaker still, with no complete inhibition observed over this concentration range. The general trend, therefore, that phosphonate additives are stronger inhibitors than sulfonate additives is upheld. 


\section{SEM at high supersaturations $(\mathrm{S}=\mathbf{2 5})$}

The same transformation in barite morphology induced by the p-phosphonated calix[4]arene occurs when the sulfonated calixarene is present, but higher concentrations are required. ${ }^{18}$ Thus, the sulfonated calixarene still has a significant impact on the morphology of the barium sulfate particles despite the

5 small change in the \% inhibition. Both result in 'square tablet'-like particles which eventually become rod-shaped as the calixarene concentration increases. ${ }^{18}$ At higher concentrations still, the presence of both calixarenes together results in barium sulfate crystals with dumbbell shapes, which can aggregate together. ${ }^{18}$ Remarkably this evolution of particle shape (rod to dumbell) is also seen in the formation of peanut shaped mesocrystals using large macromolecules rather than relatively small molecules, as di-block co-polymers. ${ }^{24,25}$

10 The up-scaling of the crystallization experiment to $4 \mathrm{~L}$ resulted in a different barium sulfate morphology for the $p$-phosphonated calix[4]arene, as long fibres. In contrast, for the sulfonated analogue at high concentration still showed the dumbbell/rod shaped particles, of about $1 \mu \mathrm{m}$ in length and $\sim 200 \mathrm{~nm}$ in width, Figure 2.
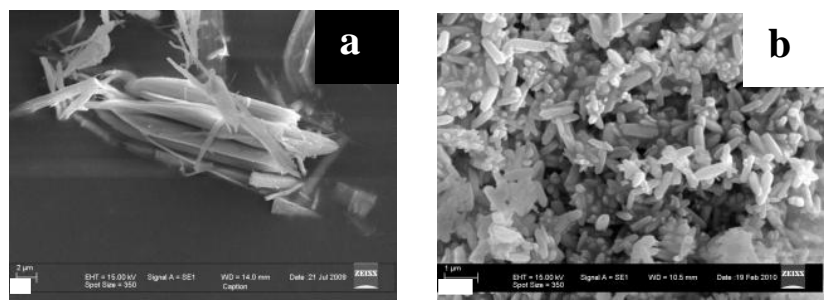

5 Figure 2. SEM of barite solids obtained from large batch samples for XRD analysis from the crystallization with (a) $0.0134 \mathrm{mmol} \mathrm{L}^{-1} p$-phosphonated calix[4]arene and (b) $0.42 \mathrm{mmol} \mathrm{L}^{-1} p$-sulfonated calix[4]arene (scale bar is $2 \mu \mathrm{m}$ and $1 \mu \mathrm{m}$ respectively)

It is unclear from the above data whether the particles formed in the presence of the sulfonated calixarene are single crystals, polycrystalline or mesocrystalline.

20

\section{XRD of particles formed at $\mathrm{S}=\mathbf{2 5}$}

The powder XRD pattern for the barite precipitate formed in the presence of $p$-sulfonated calix[4]arene is presented in Figure 3 along with the pattern for the control sample, and clearly there is line broadening. Linewidth analysis gave an average crystallite size of $215 \mathrm{~nm}$ for the control sample and $190 \mathrm{~nm}$ for the sample formed in the presence of $p$-sulfonated calix[4]arene. This correlates well with the width of the particles as seen in the SEM image. At low

25 concentrations, the calixarene does not impact greatly on the XRD pattern (see supplementary information, Fig. S1), other than to change the relative peak heights. The XRD pattern of the product obtained in the presence of $p$-phosphonated calix[4]arene has been discussed previously ${ }^{18}$ and results in a pattern consistent with an anisotropic particle showing preferred orientation effects. TEM on thin sections confirmed that the barium sulfate particles formed in the presence of $p$-phosphonato-calix[4]arene are mesocrystals. ${ }^{18}$

a

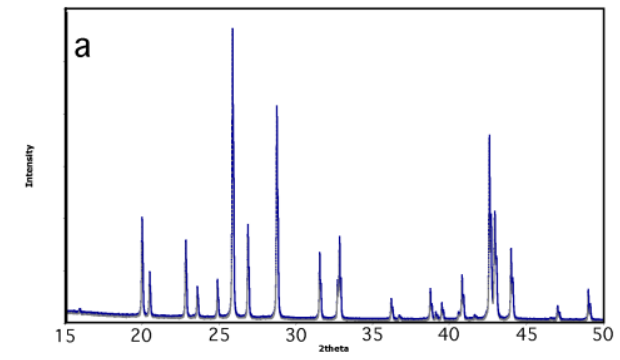

b

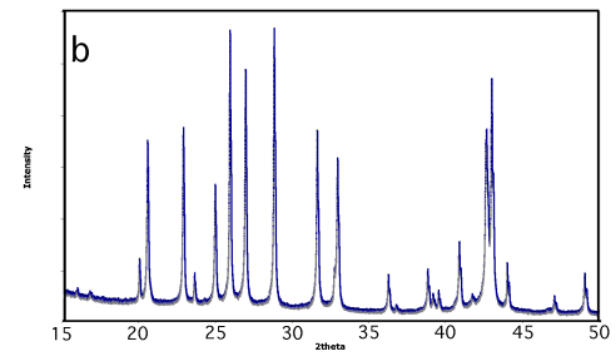

Figure 3. Powder XRD patterns of (a) barite control, (b) barite precipitated in the presence of $0.42 \mathrm{mmol} \mathrm{L}^{-1} p$-sulfonated calix[4]arene 


\section{Nephelometry (S=25)}

The measurement of absorbance at $900 \mathrm{~nm}$ (where the absorption of the solution and other species is expected to be low) can be interpreted as a turbidity value. ${ }^{22}$ The time taken before the turbidity increases above the background is known as the induction time, ${ }^{27}$ which is inversely proportional to the 5 nucleation rate. Thus, changes in induction time directly relate to bulk/homogenous nucleation and the surface free energy of the critical nuclei. ${ }^{27}$

$\mathbf{a}$

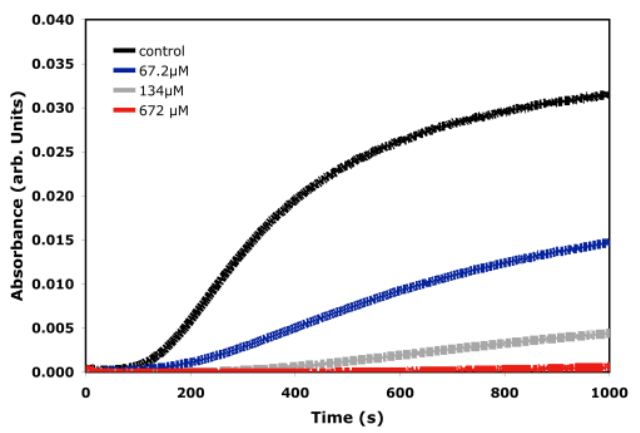

b

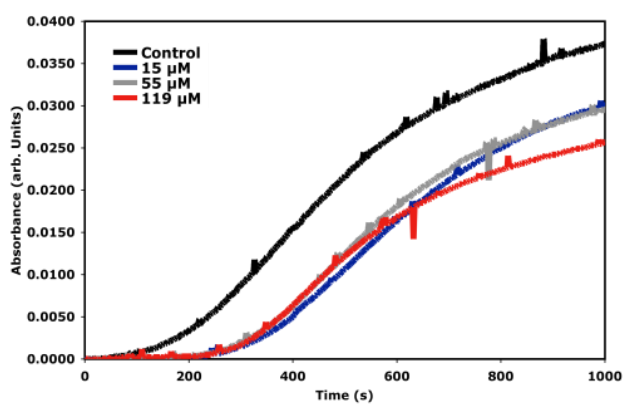

Figure 4. Absorbance versus time curves for barium sulfate crystallization in the presence of different concentrations of the calixarene molecules (a) $p$ phosphonated calix[4]arene, and (b) $p$-sulfonated calix[4]arene.

The results in Figure 4 show that the induction time increases as the concentration of the $p$-phosphonated calix[4]arene increases, and therefore this calixarene inhibits homogenous nucleation. This in turn means that it is interacting with the critical nuclei and changing the surface free energy of these nuclei. ${ }^{27}$ The sulfonated calixarene molecule has quite a different interaction. The induction time initially increases for $0.003 \mathrm{mM}$ concentrations, but no

15 significant change in the induction time occurs after this. Thus, this additive may inhibit homogenous nucleation somewhat (and will adsorb onto the critical nuclei to some extent) but has minimal impact on bulk nucleation at concentrations above $0.003 \mathrm{mM}$.

\section{TEM on particles formed at $S=25$}

The results from XRD and TEM confirm that the barium sulfate particles formed in the presence of the $p$-phosphonated calix[4]arene as being 20 mesocrystals. ${ }^{18}$ Mesocrystals are defined to be crystals that appear to diffract as a single crystal but are, in fact, made up of self-assembled, and oriented, nanoparticles. ${ }^{28}$ An important aspect of the mesocrystal formation mechanism is the stabilisation of the nanoparticles so that they have time to aggregate in such a non-random fashion.

For the $p$-sulfonated calix[4]arene, the SEM and XRD data are inconclusive with respect to defining the barium sulfate particles as mesocrystals. The line 25 broadening evident in the XRD patterns corresponds well to the width of barium sulfate particles observed using SEM. Thin sections viewed under the TEM were thus necessary to ascertain the fine detail of the structure of the particle. The particles were susceptible to significant beam damage, however (Figure 5), which could result from an uptake of organic material in the structure, namely the calixarene. More importantly, the beam damage made higher magnification imaging difficult. What was observed, however, was that although there appeared to be the gross outline of individually aligned nano-rods (as can be seen in Figure 6c and d) there were no distinctly separate rod-like particles, as observed for the phosphonated calixarene. ${ }^{18}$ 


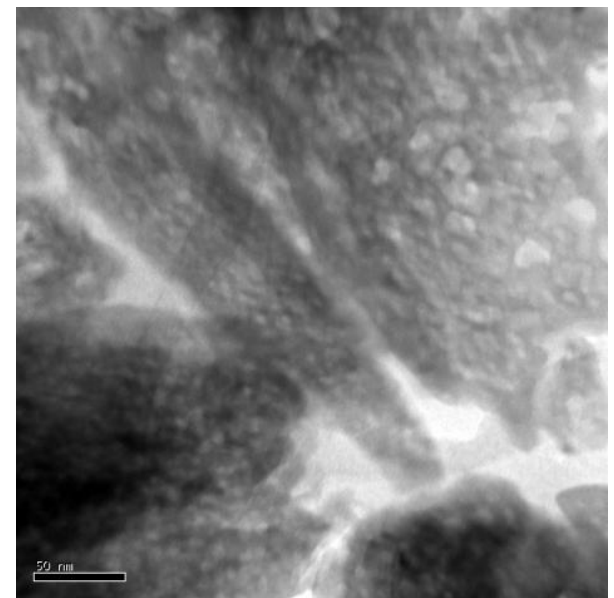

Figure 5. TEM image of particles of barite formed in the presence of the $p$-sulfonated calix[4]arene which have been damaged by the electron beam.

There is evidence that these particles are made up of filaments of smaller particles (Figure $\mathbf{6 c}$ and $\mathbf{d}$ ) but the internal structure is mainly porous. Clearly 5 smaller particles and fibres are part of the structure, but overall these smaller particles are not separated from each other. This can be seen more clearly in Figure 6b. We conclude, therefore, that this structure may have been a mesocrystal but has subsequently been fused to a large extent. Selected area diffraction showed crystallinity as expected.
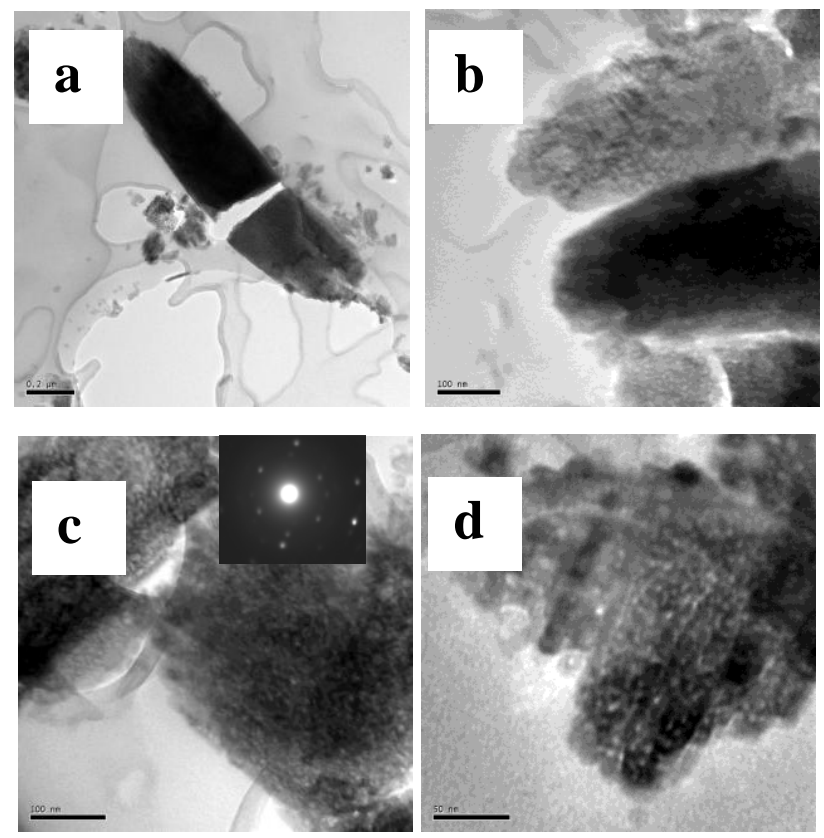

Figure 6. TEM images of barium sulfate formed in the presence of $p$-sulfonated calix[4]arene $(0.42 \mathrm{mM})$ and selected area diffraction of the area shown in $(d)$.

15 Thus, we hypothesise that the sulfonated calixarene initially forms mesocrystals of barium sulfate, but over time they fuse. They are also subject to electron beam damage, unlike the more robust discrete mesocrystals formed in the presence of the phosphonated calixarene.

\section{Impact of $p$-sulfonated calix[4]arene on barium sulfate particles formed at $\mathrm{S}=5$}

In order to confirm or refute the possibility that $p$-sulfonated calix[4]arene is able to form mesocrystals at all, lower supersaturated barium sulfate 20 solutions were prepared to enhance the impact of the calixarene. We now find that the sulfonated calixarene forms structures that appear to be a mixture of mesocrystals and single crystals Figure 7. In this sample, small bow-tie looking particles were found, although as a minor component. 

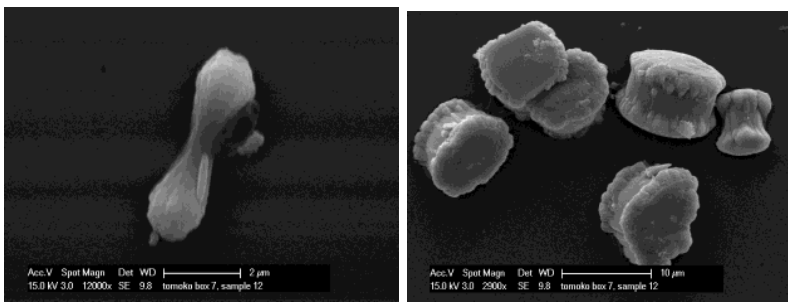

Figure 7. SEM images of barium sulfate particles formed in the presence of $0.10 \mathrm{mM} \mathrm{Ba}^{2+}$ and $\mathrm{SO}_{4}{ }^{2-}, 0.03 \mathrm{mM} p$-sulfonated calix[4]arene at $\mathrm{pH} 6$.

We would surmise then that $p$-sulfonated calix[4]arene induced mesocrystal structures are somehow different to those of the phosphonated analogue in 5 that the nanoparticle fibres fuse over time. This suggests two possibilities; either

$p$-sulfonated calixarene does not self aggregate to the same degree as the phosphonated calixarene, meaning the originally formed nanoparticles then are not stabilised with respect to aggregation and fusion, or

$p$-sulfonated calix[4]arene aggregates do not interact as strongly with the barium sulfate surface.

The first possibility is less likely since this would lead to random aggregation and this is not observed. In general, complexes formed with $p$-sulfonated 10 calix[4]arene show similar bilayer structures to the phosphonated analogue,$^{29,30,31}$ but they also can assemble into more complicated structures in the presence of metals ions, forming tubular, ${ }^{32}$ and icosahedral and cuboctahedral arrays of twelve calixarenes, ${ }^{32,33}$ and complicated extended structures. ${ }^{34}$ Moreover, $p$-phosphonated calix[4]arene is a powerful surfactant for metal nanoparticles, and in stabilising graphene sheets, ${ }^{35}$ through association in $2 \mathrm{D}$ arrays. These distinct differences between the two isostructural calixarenes presumably relate to their different self assembly preferences in the presence of metal ions. While no complexation constant data is available for barium ions in the presence of the phosphonated or sulfonated calixarene, the higher 15 charge of the phosphonated calixarene would suggest a stronger interaction with barium ions.

\section{$\operatorname{AFM}(\mathbf{S}=5)$}

AFM investigation allows the in situ observation of 2D nucleation processes and crystal growth both in the presence and absence of the calixarene molecules. While this is desirable, it must be remembered that the results pertain only to the face on which the visualization occurs and does not 20 necessarily relate to the crystal as a whole. The growth rate was calculated along the slowest growth direction for barium sulfate growth islands, being in the $\langle 100\rangle$ direction.

The AFM images show that the presence of either of the calixarene molecules does not change the 2D growth island shape (Figure 8).

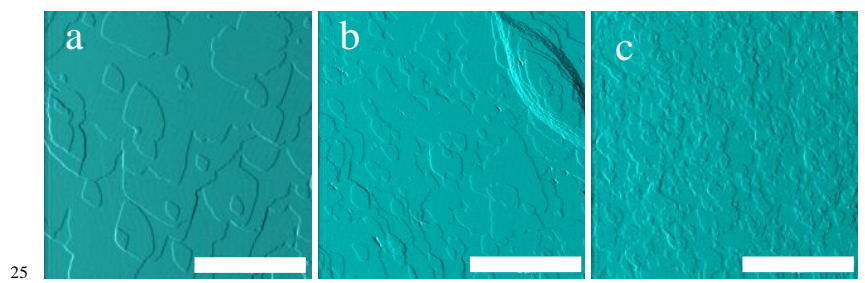

Figure 8. AFM deflection images obtained on the (001) face of barium sulfate (a) in the absence of any additives and in the presence of (b) $0.008 \mathrm{mM} p$ sulphonated calix[4]arene or (c) $0.005 \mathrm{mM} p$-phosphonated calix[4]arene. Size bars are $2 \mu \mathrm{m}$ for all images

For $p$-sulfonated calix[4]arene, $10 \mathrm{ppm}$ and $20 \mathrm{ppm}$ concentrations were initially investigated since higher concentrations appeared to be required for this 30 compound than the phosphonated analogue to observe any effects. At $20 \mathrm{ppm}$, however, the (001) growth was already reduced to zero and a small amount of dissolution was also observed on one occasion. Growth is promoted on this face by both calixarene molecules (Figure 9) but more so by $p$ phosphonated calix[4]arene, particularly when the concentration differences are taken into consideration. The promoting effect at $0.015 \mathrm{mM} p$-sulfonated calix[4]arene was $\sim 50 \%$ while less than $0.002 \mathrm{mM}$ of the phosphonated analogue resulted in promotion close to $100 \%$ of the control value. At higher concentrations, the presence of both calixarene molecules results in inhibition and dissolution being observed for the barium sulfate (001) face, although at 35 the same time the surface becomes rougher and the images difficult to interpret. In fact both calixarenes promote $2 \mathrm{D}$ nucleation on this surface, as is evident in Figure 7c, and the analysis of both growth rates and 2D nucleation rates become quite difficult. However, growth promotion followed by inhibition has also been observed for larger polyaspartic molecules on calcium carbonate, ${ }^{36}$ as well as for barium sulfate in the presence of aspartic acid. ${ }^{37}$ 


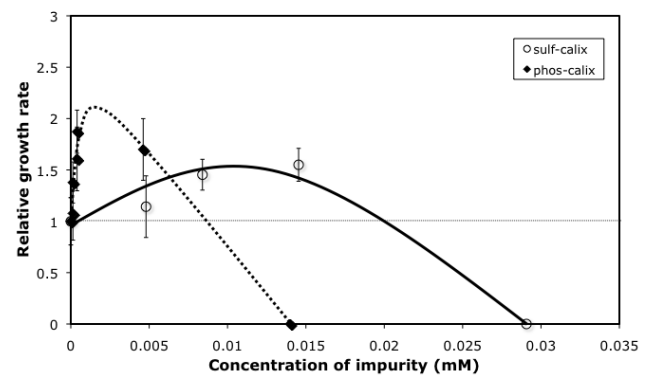

Figure 9. Relative growth rate in the $<100>$ direction on the (001) face of barium sulfate, derived from AFM images (lines drawn to aid reader only).

Flushing the freshly precipitated surfaces with water results in partial dissolution of the crystal along defect lines for the solids grown in the presence of $p$ 5 phosphonated calix[4]arene but not for the sulfonated analogue (observed for up to an hour) at the concentrations shown (Supplementary Information Fig. S2). This suggests a possible incorporation of the phosphonated calixarene despite a lack of impact on the growth island shape. However, step height analysis established an average step height of 3.79 and $3.69 \AA$ for the sulfonated and phosphonated calixarenes respectively, and while both are higher than that of the control, $3.61 \AA$, all the values are within the error of the measurement (standard deviation varied from $0.2-0.4 \AA$ ).

10 Atomic resolution imaging of the barium sulfate crystal grown in the presence of $p$-sulfonated calix[4]arene revealed spacings comparable to that expected for pure barium sulfate. In the case of the phosphonated analogue, this is altered significantly, ${ }^{18}$ with the AFM image being consistent with a structure where a layer of phosphonated calixarenes, most likely as the ubiquitous bilayer, is modified by the inclusion of barium and/or sulfate ions. This would also be consistent with the phosphonated calixarene resulting in more soluble barium sulfate surfaces, which suggests that the incorporation of the calixarene resulting in defects in the structure affords a more soluble solid. We have previously shown that charge stabilization is not a possible 15 mechanism, and that self-assembly of the calixarene molecule is the most likely mechanism of stabilisation. ${ }^{18}$

AFM results also show 2D nucleation promotion for both the phosphonated and sulfonated calixarene (see Supplementary Information Fig. S3). Thus while the nephelometry results suggest that 3D nucleation is inhibited, on the (001) face at least 2D nucleation appears to be promoted. The greater growth and nucleation rate on the (001) face would explain why rod shaped particles form in the presence of these two additives.

In the case of $p$-sulfonated calix[4]arene, the barium sulfate behaves similarly in that crystallization is initially promoted and subsequently inhibited at higher concentrations. Thus, the crystallization behaviour, as determined from the AFM results, does not help elucidate why the internal structure of the barium sulfate particles are dramatically different to those formed in the presence of the phosphonated calixarene. The major difference here is that the atomic resolution images when the sulfonated calixarene is present is equivalent to the control, which implies that the AFM tip is removing the calixarene

25 from the surface. This could indeed be occurring since these AFM images are obtained in contact mode, and this combined with a weaker interaction of the sulfonated calixarene on the surface could explain why AFM images show no differences at atomic resolution despite the TEM images clearly suggesting incorporation of the organic compound during crystallization. The AFM results may therefore be underestimating the impact of the sulfonated calixarene on barium sulfate crystallization. At low resolution, AFM imaging also found some interesting features; namely the slow appearance of holes within the structure which are observed for either the control or in the presence of $p$-phosphonated calix[4]arene. In viewing Figure $7 \mathrm{~b}$ at a higher

30 magnification we notice holes, which appear over time (some of these have been highlighted in Figure 9), and may mean that the sulfonated calixarene is incorporated into the barium sulfate structure as a bulk impurity without altering the structure. This hypothesis is shown schematically in the "bricks and mortar' analogy next to the image and has some support both in the TEM image porosity observed in the presence of the sulfonated calixarene, and in the lack of atomic resolution differences observed using AFM. Alternatively the bulk impurity could be some assemblies of the aforementioned arrays of the calixarene. ${ }^{32,33}$ This was further investigated by conducting thermogravimetric analysis on the barium sulfate with the calixarene molecules present. It was 35 found that at most $3.5 \%$ of the solid was $p$-sulfonatocalix[4]arene (as determined by the weight loss up to $800^{\circ} \mathrm{C}$ ) while $5.3 \%$ of the mass was due to the presence of phosphonated calixarene. This is despite the fact that the $p$-phosphonatocalix[4]arene was present at less than one tenth of the concentration of the sulfonated calixarene in the large batch preparation $(0.0134 \mathrm{mM}$ versus $0.42 \mathrm{mM})$ highlighting the much stronger interaction of the phosphonated calixarene with the barium sulfate surface.

40 The results discussed thus far are consistent with the sulfonated calixarene being present with barium sulfate (AFM, TEM and TGA results) and that it does not alter the unit cell dimensions (as determined by XRD and AFM). Overall, this supports the hypothesis proposed that the sulfonated calixarene is present as a separate phase to the barium sulfate. 


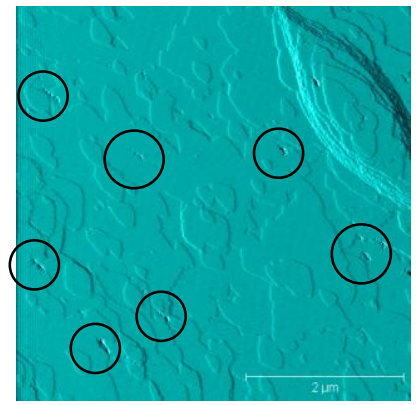

(a)

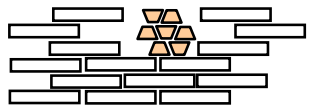

(b)

Figure 10. (a) Higher magnification image of Figure $7 \mathrm{~b}$ and (b) a schematic showing how the aggregated $p$-sulfonated calix[4]arene might be incorporated into the barium sulfate structure (bricks) without altering the bulk structure or lattice parameters.

\section{Conclusions}

In the present study both the calix[4]arene macrocycles have been shown to promote growth on the (001) face, resulting in rod shaped particles. These rod-shaped particles can become the core particles for subsequent superstructures, which are not randomly aggregated but orient to form the dumbbell or fibre shapes. In addition, we have established that $p$-sulfonated calix[4]arene is a much weaker inhibitor than the phosphonated analogue, and this supports 10 earlier literature results on the impact of the different functional groups on the upper rim of the calixarenes.

Nephelometry shows that the calixarenes adsorb onto the critical nuclei, and inhibit bulk homogenous nucleation. The weaker interaction for the sulfonated calixarene is seen once again in the impact on induction times. The phosphonated calixarene lengthens the induction times far more than the sulfonated molecule, and thus, the sulfonated calixarene has only limited impact on homogenous nucleation.

15

XRD and TEM results for the barium sulfate crystallized in the presence of $p$-phosphonated calixarene established that the particles were mesocrystals. ${ }^{18}$ Remarkably, the sulfonated calixarene does not show distinct nanoparticle fibres, which have aggregated together; although the fibres are sometimes visible, they appear to be fused. We hypothesise that inherently unstable mesocrystals are formed, which fuse over time.

20 The AFM results clearly show that the calixarenes have a strong interaction with the (001) barite face, initially promoting its growth before inhibiting it. In the case of $p$-phosphonated calix[4]arene, AFM confirms that the surface is impacted on by the organic molecule, changing both its solubility and its surface atomic structure. ${ }^{18}$ Despite the AFM showing little change in the atomic resolution images with and without added sulfonated calixarene, the beam damage caused in the TEM, the TGA and the AFM results, suggest that the sulfonated calixarene is also incorporated during barium sulfate crystal growth. It is possible that since these images were taken in contact mode, the AFM tip removed the sulfonated calixarene molecules from the surface. This 25 would support an overall conclusion that the sulfonate calixarene molecule is more weakly bound than the phosphonated calixarene to the barium sulfate (001) surface. Nevertheless, it is also possible that the sulfonated calixarene does not substitute into the lattice but rather is present as a secondary solid phase. This would explain the presence of significant porosity within the barium sulfate structure and the lack of impact of the sulfonated calixarene on the atomic resolution images of the (001) surface. Such porous barium sulfate structures in the presence of impurities have previously been observed. ${ }^{38}$

30 It is also possible that the sulfonated calixarene is both weakly bound and is present as a secondary solid phase, and that this results in the formation of mesocrystals which fuse over time, becoming more and more single crystal in nature. The similarity in the behaviour of the two calixarenes in terms of changes in barium sulfate morphology leads to the conclusion that their different final impacts relate to different strength of interaction with the surface of the material. Given the similarity in backbone structure as isostructural bowl shaped molecules, these differences are not associated with lattice matching differences or any significant stereochemical differences between the sulfonate or phoshponate group, but instead to the charge difference. In terms of the

35 structure-activity relationships of these molecules and their impact on barium sulfate crystallization, it appears from this work that charge controls the strength of interaction with the surface and that when the charge is lowered, so too is the interaction of the molecule with the surface.

Finally, we note that both calixarene molecules increase the growth rate of the barium sulfate (001) face and promote 2D nucleation on this surface. In addition, the $p$-phosphonated calix[4]arene is far more potent in this regard than $p$-sulfonated calix[4]arene. Thus, while 3D nucleation may be inhibited 40 by these molecules, 2D nucleation is not. 


\section{Acknowledgements}

We would like to thank Peter Chapman for the TGA analysis and acknowledge the Curtin Centre for Materials Research for use of the SEM, TEM and XRD facilities. We would also like to acknowledge Dr Tom Becker for the use of the AFM facilities and the Australian Research Council for support of the work.

\section{References}

1. N. Rodriguez-Hornedo, D. Murphy (1999), J. Pharm. Sci., 88 651-660.

2. S. Mann (2001) in Biomineralization: Principles and Concepts in Bioinorganic Materials Chemistry, Oxford University Press, ISBN 0198508824.

3. S. Weiner, L. Addadi (1997), Journal of Materials Chemistry, 7 (5) 689-702.

10 4. A. H. L. Chow, H. H. Y. Tong, P. Chattopadhyay, B. Y. Shekunov (2007), Pharmaceutical Research, 24(3) 411-437.

5. J. D. Grobler, J. B. Bosman (2011), The Journal of The Southern African Institute of Mining and Metallurgy, 111 401-408.

6. S. I. Heo, J. C. Yun, K. S. Oh, K. S. Han (2006), Advanced Composite Materials, 15(1) 115-126.

7. U. Ulusoy, M. Yekeler, C. Hiçyılmaz (2003) Minerals Engineering, 16(10) 951-964.

8. H. Cölfen, L. Qi (2001), Chem. Eur. J., 7(1) 107-116.

15 9. F. Jones, M. I. Ogden (2010), CrystEngComm., 12,1016-1023.

10. F. Jones, P. Jones, M. I. Ogden, W. R. Richmond, A. L. Rohl, M. Saunders (2007) Journal of Colloids and Interface Science, 316 553-561.

11. G. M. Graham, L. S. Boak, K. S. Sorbie (1997), Int. Symp. Oilfield Chem.; Society of Petroleum Engineers: USA, 611-626.

12. M. Bertram, J. Cowen (1998), Aquatic Geochem., 4 455-468.

13. J. D. Hopwood, S. Mann, A. Gooday (1997), J. Mar. Biol. Ass. UK, 77 969-987.

20 14. S. Sanchez-Moral, L. Luque, J. Canaveras, L. Laiz, V. Jurado, B. Hermosin, C. Saiz-Jimenez (2004), Ann. Microbiol., 54 1-12.

15. A. Baynton B. D. Chandler, F. Jones, G. Nealon, M. I. Ogden, T. Radomirovic, G. K. H. Shimizu J. M. Taylor (2011), CrystEngComm., 13, 10901095.

16. S. R. Freeman, F. Jones, M. I. Ogden, A. Oliviera, W. R. Richmond (2006), Crystal Growth \& Design, 6 2579-2587.

17. F. Jones, J. Clegg, A. Oliviera, A. L. Rohl, M. I. Ogden, G. M. Parkinson, A. M. Fogg, M. M. Reyhani (2001), CrystEngComm., 3(40) $165-167$.

25 18. A. Baynton, T. Radomirovic, M. I. Ogden, C. L. Raston, W. R. Richmond, F Jones (2011), CrystEngComm., 13 109-112.

19. S. Shinkai, K. Araki, T. Tsubaki, T. Arimura, O. Manabe (1987), J. Chem. Soc. - Perkins Trans., 1(11) 2297-2299.

20. T. E. Clark, M. Makha, A. N. Sobolev, H. Rohrs, J. L. Atwood, C. L. Raston, (2008), Chem. Eur. J., 14 3931-3938.

21. K. I. Parsiegla, J. L. Katz (1999), J. Crystal Growth, 200(1-2) 213-226.

22. K. C. Yang, R. Hogg (1979), Analytical Chemistry, 51(6) 758-763.

30 23. F. Jones, A. Oliveira, A. L. Rohl, G. M. Parkinson, M. I. Ogden, M. M. Reyhani (2002), J. Crystal Growth, 237-239 424-429.

24. L. Qi, H. Cölfen, M. Antonietti (2000), Angew. Chem. Int. Ed., 39 604-607.

25. L. Qi, H. Cölfen, M. Antonietti (2000), Chem. Mater., 12 2392-2403.

26. J. W. Mullin (1961), Nucleation. In Crystallization, 3rd ed.; Butterworth-Heinemann: Oxford, pp 172-201.

27. M. Niederberger, H. Cölfen (2006), Phys. Chem. Chem. Phys., 8, 3271-3287.

35 28. J. L. Atwood, L. J. Barbour, M. J. Hardie, C. L. Raston (2001), Coordination Chemistry Reviews, 2223 - 32.

29. F. Perret, A. N. Lazar, A. W. Coleman (2006), Chem.Commun., 2425-2438.

30. S. Elhadj, J. J. De Yoreo, J. R. Hoyer, P. M. Dove (2006), PNAS, 103(51) 19239-19242.

31. A. D. Martin, C. L. Raston (2011) Chem. Commun., 47 DOI: 10.1039/c1cc12048d.

32. G. W. Orr, L. J. Barbour, J. L. Atwood (1999) Science 285, 1049-1052.

40 33. J. L. Atwood, L. J. Barbour, S. J. Dalgarno, M. J. Hardie, C. L. Raston, H. R. Webb (2004) J. Am. Chem. Soc., 126, $13170-13171$.

34. I. Ling, Y. Alias, C. L. Raston (2010) New J. Chem., 34, 1802-1811.

35. J. Zou, A. D. Martin, B. Zdyrko, I. Luzinov, C. L. Raston, K. S. Iyer (2011) Chem Commun., 47, 5193-5195.

36. S. Piana, F. Jones, J. D. Gale (2007), CrystEngComm., 9 1187-1191.

37. F. Jones, W. R. Richmond, A. L. Rohl (2006), J. Phys. Chem. B, 110 7414-7424.

45 38. W. J. Benton, I. R. Collins, I. M. Grimsey, G. M. Parkinson, S. A. Rogers (1993), Faraday Discussions, 95 281-297. 